\title{
Ultrasonic Inspection of the LTAB Floor
}

Graham Thomas

u.s. Department of Energy July 31, 2001

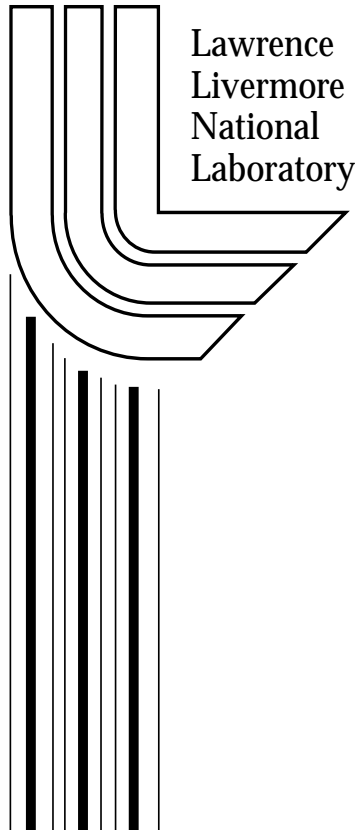




\section{DISCLAIMER}

This document was prepared as an account of work sponsored by an agency of the United States Government. Neither the United States Government nor the University of California nor any of their employees, makes any warranty, express or implied, or assumes any legal liability or responsibility for the accuracy, completeness, or usefulness of any information, apparatus, product, or process disclosed, or represents that its use would not infringe privately owned rights. Reference herein to any specific commercial product, process, or service by trade name, trademark, manufacturer, or otherwise, does not necessarily constitute or imply its endorsement, recommendation, or favoring by the United States Government or the University of California. The views and opinions of authors expressed herein do not necessarily state or reflect those of the United States Government or the University of California, and shall not be used for advertising or product endorsement purposes.

This work was performed under the auspices of the U. S. Department of Energy by the University of California, Lawrence Livermore National Laboratory under Contract No. W-7405-Eng-48.

This report has been reproduced directly from the best available copy.

Available electronically at http://www.doc.gov/bridge

Available for a processing fee to U.S. Department of Energy

And its contractors in paper from

U.S. Department of Energy

Office of Scientific and Technical Information

P.O. Box 62

Oak Ridge, TN 37831-0062

Telephone: (865) 576-8401

Facsimile: (865) 576-5728

E-mail: reports@adonis.osti.gov

Available for the sale to the public from

U.S. Department of Commerce

National Technical Information Service

5285 Port Royal Road

Springfield, VA 22161

Telephone: (800) 553-6847

Facsimile: (703) 605-6900

E-mail: orders@ntis.fedworld.gov

Online ordering: http://www.ntis.gov/ordering.htm

OR

Lawrence Livermore National Laboratory

Technical Information Department's Digital Library

http:/ / www.llnl.gov/tid/Library.html 
NIF 0068294

\title{
Ultrasonic Inspection of the LTAB Floor
}

\author{
Graham Thomas
}

\section{Introduction}

The National Ignition Facility's (NIF) floor is damaged by transporter operations. Two basic operations, rotating the wheels in place and traversing the floor numerous times can cause failure in the grout layer. The floor is composed of top wear surface (Stonhard) and an osmotic grout layer on top of concrete, Fig. 1. An ultrasonic technique was implemented to assess the condition of the floor as part of a study to determine the damage mechanisms. The study considered damage scenarios and ways to avoid the damage. A possible solution is to install thin steel plates where the transporter traverses on the floor. These tests were conducted with a fully loaded transporter that applies up to 1300 psi loads to the floor.

A contact ultrasonic technique evaluated the condition of the grout layer in NIF's floor. Figure 1 displays the configuration of the ultrasonic transducer on the floor. We inspected the floor after wheel rotation damage and after wheel traversal damage. Figure $2 \mathrm{a}$ and $2 \mathrm{~b}$ are photographs of the portable ultrasonic system and data acquisition. We acquired ultrasonic signals in a known pristine area and a damaged area to calibrate the inspection. Figure 3 is a plot of the typical ultrasonic response from an undamaged area (black) overlapped with a signal (red) from a damaged area. The damage area data was acquired at a location next to a hole in the floor that was caused by the transporter. Five megahertz pulses are propagated from the transducer and through a Plexiglas buffer rod into the floor. The ultrasonic pulse reflects from each discontinuity in the floor. The ultrasonic signal reflects from the top surface, the *Stonhard-to-grout interface, and the grout to concrete interface. We expect to see reflections from each of these interfaces in an undamaged floor. If the grout layer pulverizes then the high frequency signal cannot traverse the layer and the grout to concrete interface signal will decrease or vanish. The more damage to the grout the more the signal will be reduced. A secondary effect might show in the Stonhard-to-grout interface reflection. As the grout layer pulverizes the strength of the Stonhard-to-grout interface signal may increase because Stonhard-to-air is a stronger reflector that the Stonhard-togrout. This waveform may also distort because of small particles of the grout adhering to the Stonhard surface. We have experienced both these effects.

*Stonhard USA: 1-800-257-7953 


\section{Transducer}

\section{Plexiglas buffer rod}

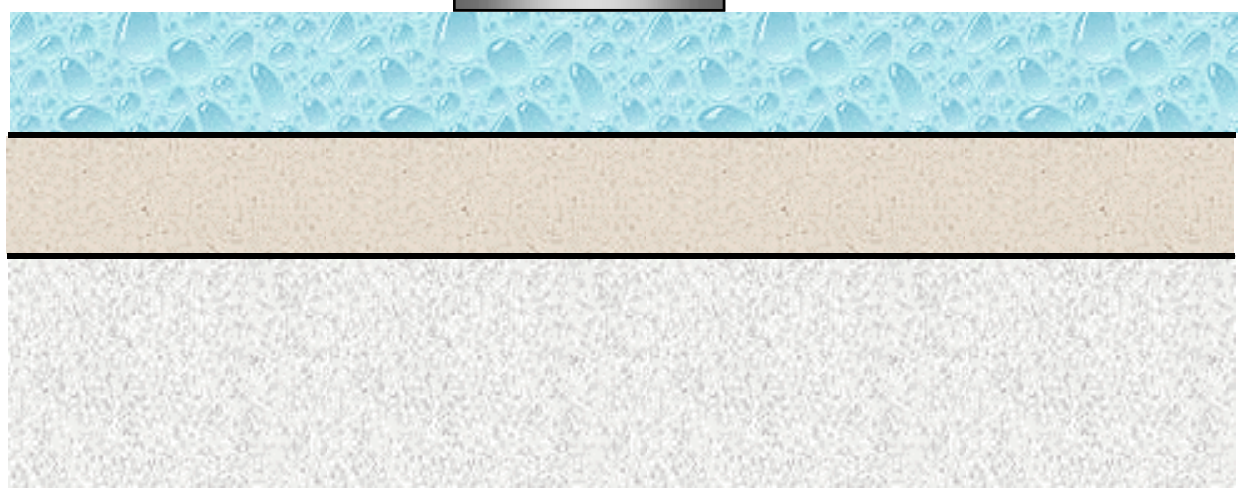

\section{Stonhard}

\section{Grout}

\section{Concrete}

Figure 1. A cross-sectional view of NIF floor with ultrasonic transducer on a Plexiglas buffer rod. The buffer rod allows us to capture a surface reflection from the buffer rod to floor interface that acts as a reference signal. We also capture reflections from the Stonhardto-grout interface and the grout to concrete interface. The grout layer must be intact for the ultrasonic energy to propagate through it and reflect off the grout to concrete interface.

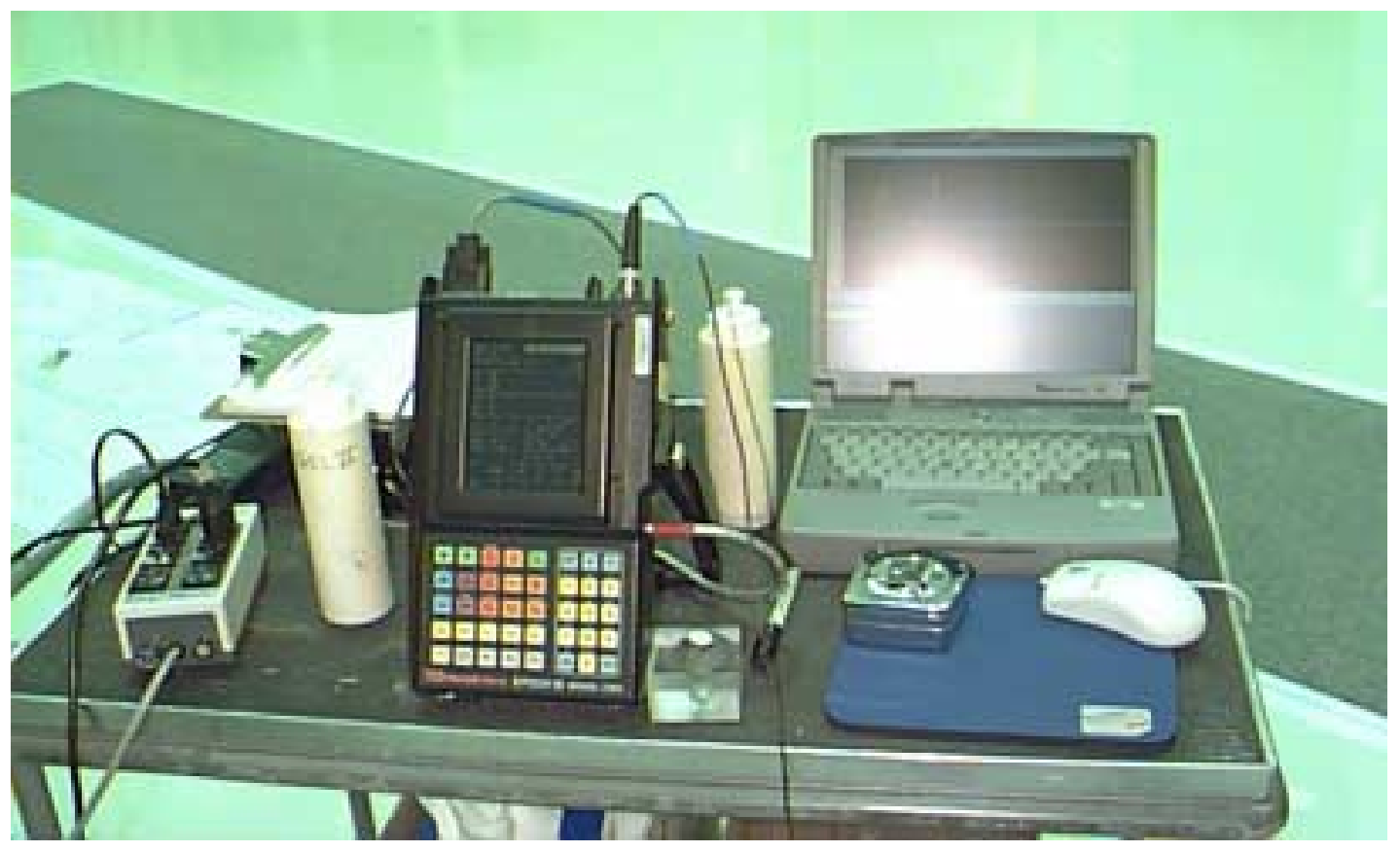

Figure 2a. Photograph of the portable ultrasonic data acquisition system. The ultrasonic data was captured on a laptop computer for analysis. 


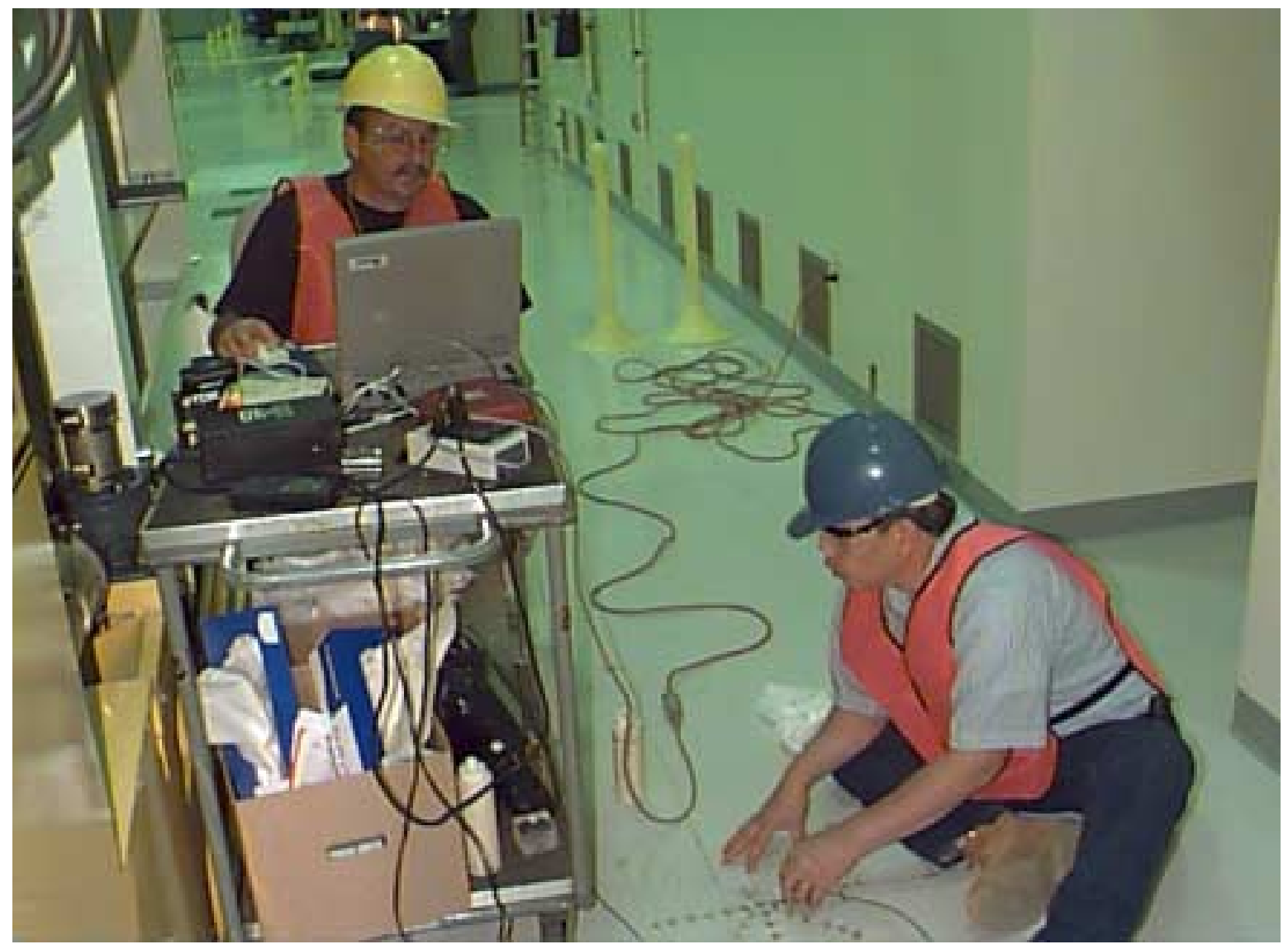

Figure 2b. Photograph of ultrasonic data acquisition on NIF's floor. 


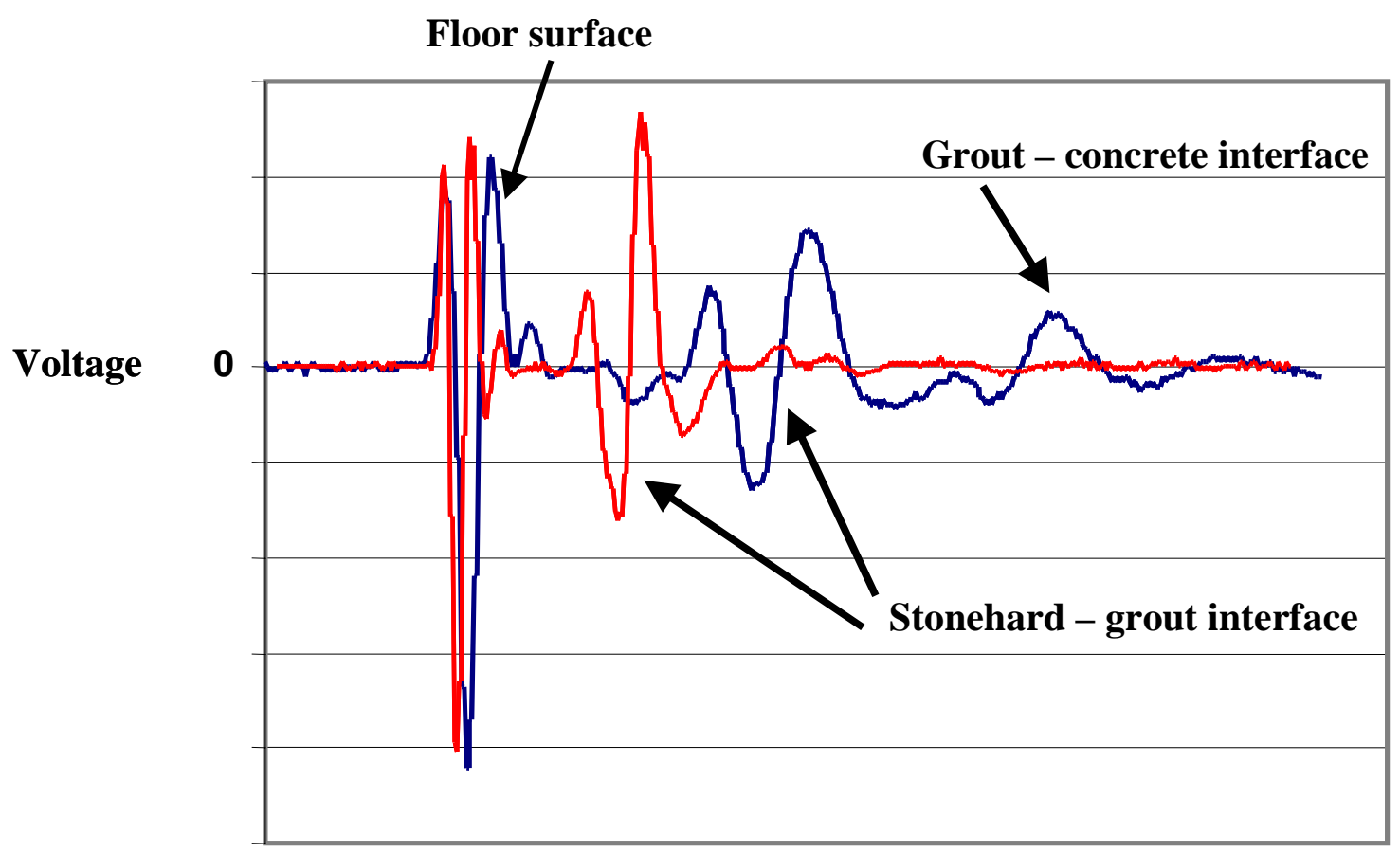

Time $(\mu \mathrm{sec})$

Figure 3. Typical ultrasonic responses from damaged (red) and undamaged (blue) sections of the NIF floor. Note the absence of the grout to concrete signal in the damaged floor signal. Also note the change in amplitude and location of the Stonhard-to-grout signal. The shorter time between the floor surface signal and the Stonhard-to-grout interface signal denotes a thinning of the Stonhard coating. The increase in amplitude indicates that there is more air at the interface in the damaged (red) signal.

\section{Rotation experiment}

The first experiment was designed to determine the floor's response to turning the wheels in the same location. The transporter wheels were rotated 90 degrees and back 90 degrees this constitutes one 'turn') and the transporter was moved laterally off the area to allow access to the floor. We ultrasonically evaluated the floor after each rotation of the wheels for a total of 16 turns. Each time we cleaned the floor after the ultrasonic measurement was performed. We did not sense any degradation to the grout layer on the side were the floor was cleaned during this experiment. The surface of the floor showed minor wear after 12 rotations, see Fig. 4. The other wheel area was not cleaned and the floor experienced significant damage, see Fig. 5. Note that the damage in the area that was not cleaned showed obvious evidence of sub-surface delamination: a bubble appeared and a hollow sound was made when the floor was tapped. 


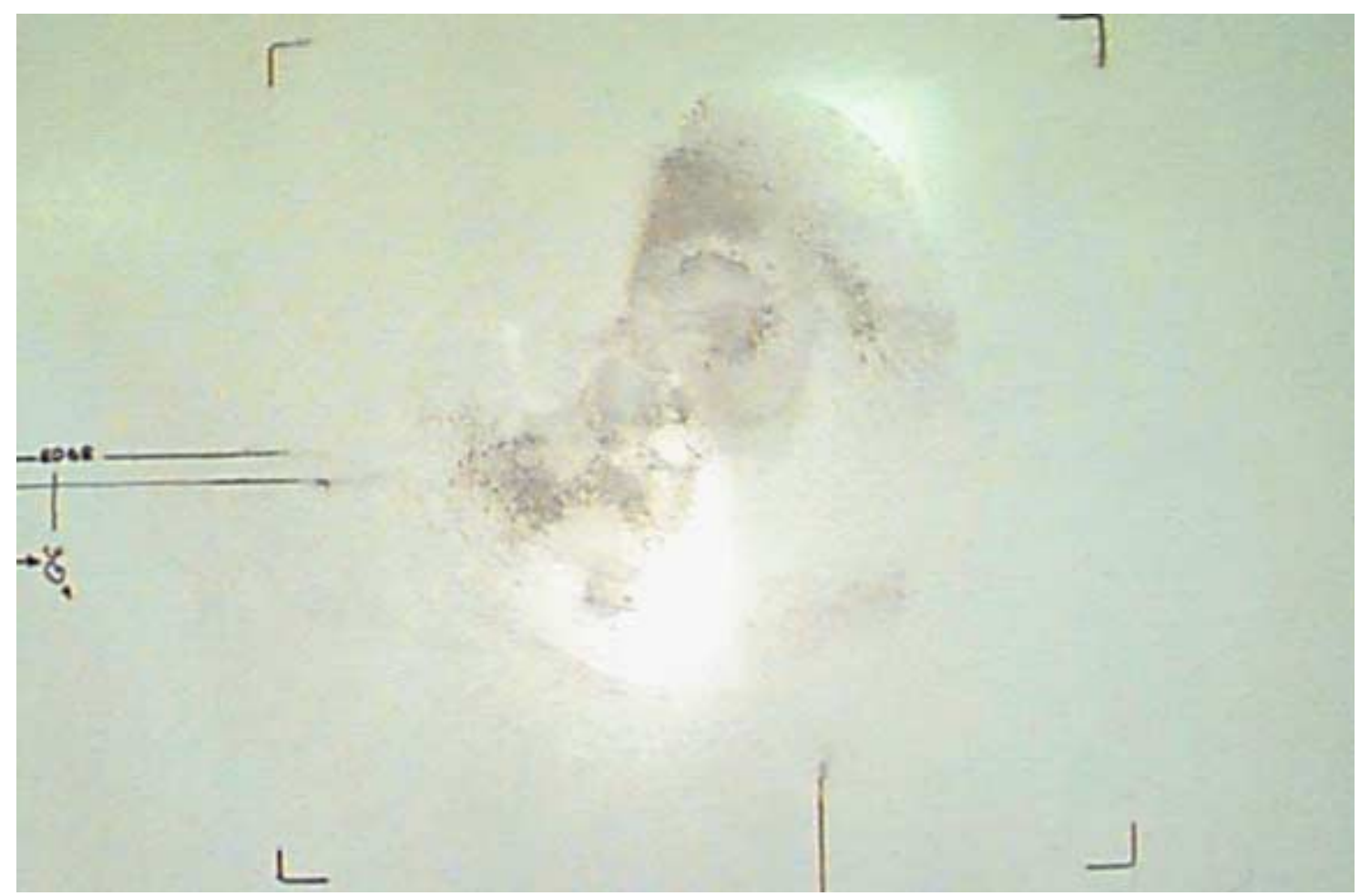

Figure 4. Floor surface after 12 rotations with the floor cleaned after each rotation.

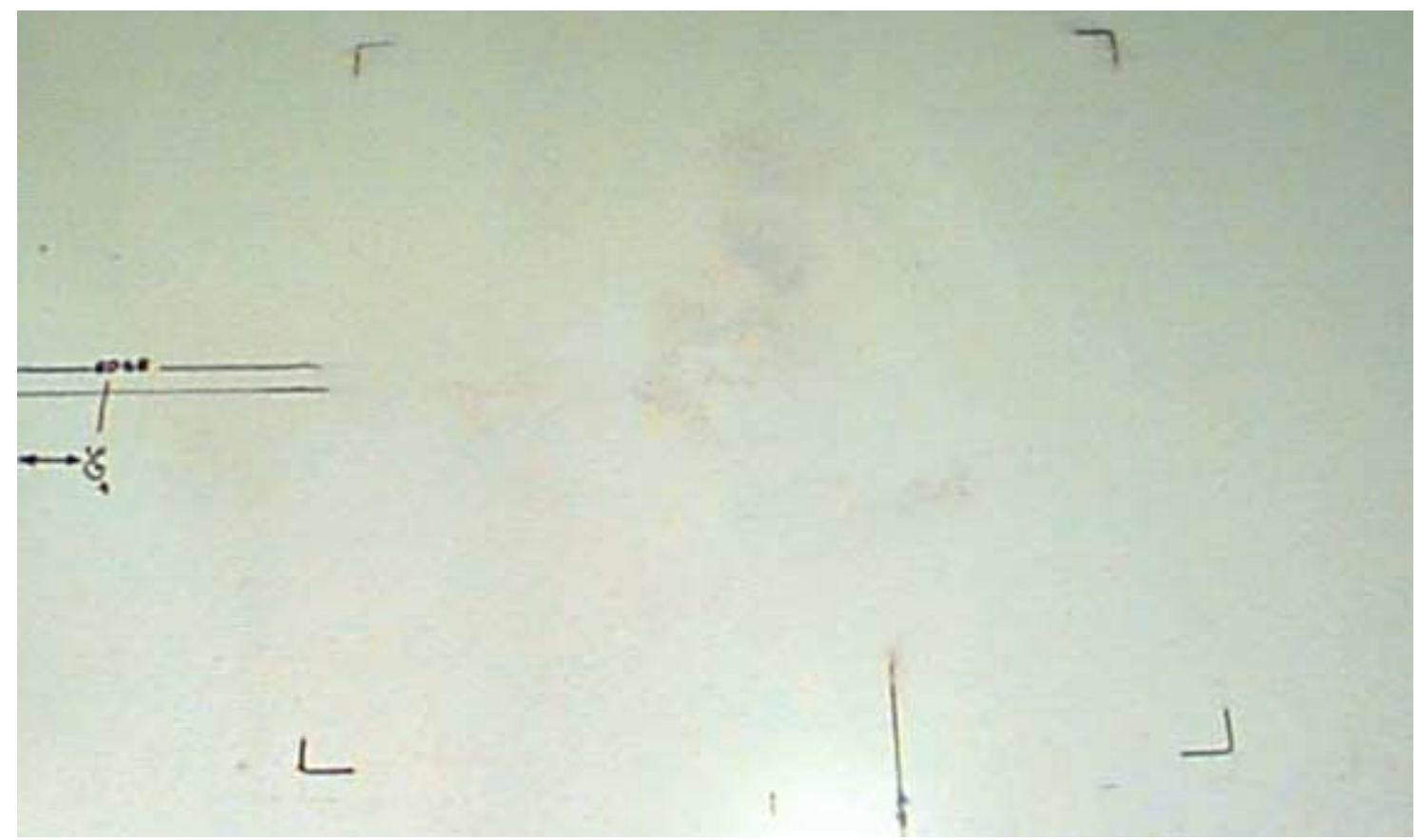

Figure 5. Floor surface after 16 rotations. The floor was not cleaned after each rotation. 
A potential solution to the rotating wheel damage is to place a thin steel plate on the floor where the wheel pivots. We conducted a second experiment where thin steel plates were attached to the floor with double-backed tape at the location of the wheel-turning, see Fig. 6. Ultrasonic evaluations were conducted at intervals up to a total of one hundred turns and no damage was detected in the grout layer.

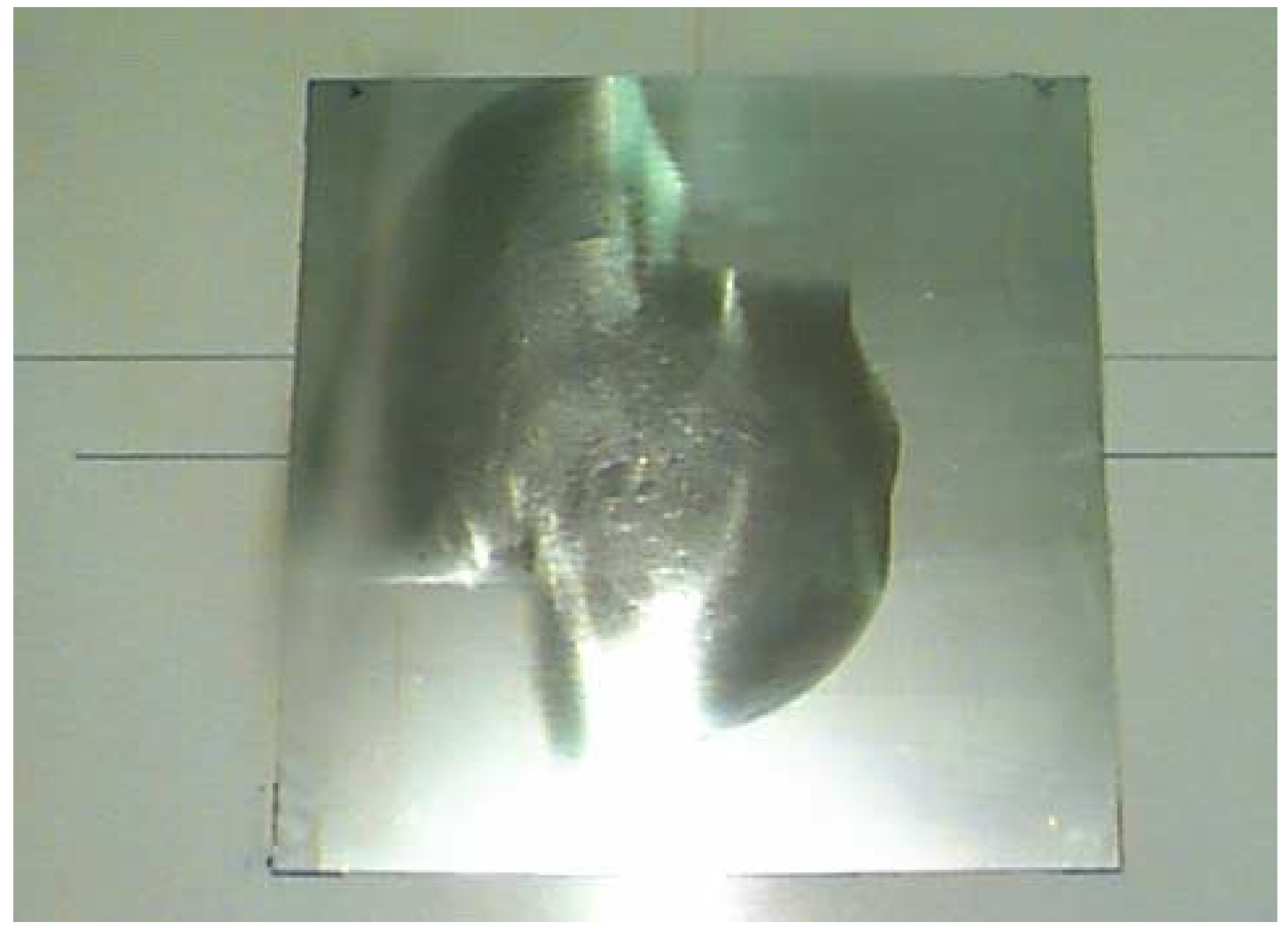

Figure 6. Photograph of steel plate after transporter wheel pivoted 50 times in place.

\section{Traverse experiment}

An experiment was conducted to determine the susceptibility of the floor to damage as the transporter moved across the floor. A test sequence was established to measure the ultrasonic signals after up to 1000 passes over the same location on the floor. Appendix A details the experimental sequence. We monitored the start-stop location as well as two locations along the path. A grid template was placed at the locations shown in Fig. 7 and described in Appendix B. We detected damage in the grout layer in isolated areas in a little as 32 passes. There were distinct ultrasonic indications of grout damage in several areas after 500 passes. Figures 7 and 8 graphically depict the ultrasonic measurement sites and the qualitative damage assessment. The next measurement interval was to be at 1000 passes. The floor failed catastrophically at around 900 passes. Figure 8 depicts the ultrasonic evaluation at the same locations as well as at locations under the other wheels. We ultrasonically evaluated the other wheel's track and could sense the deterioration of the grout layer. Figure 8 shows that most of the subsurface damage occurs under the loaded 
wheels and little damage occurs between the wheels. Figure 9 is a map of the locations that ultrasonic data were acquired. Figure 10 is a photograph of the damaged floor.

- Good

Slight damage

- Major damage

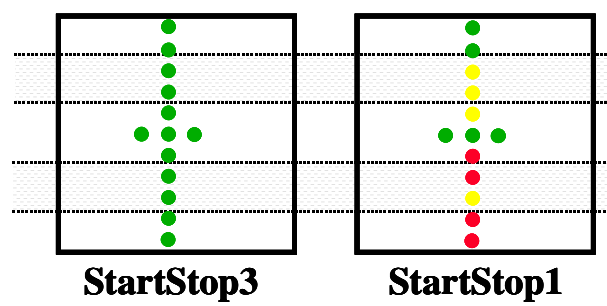

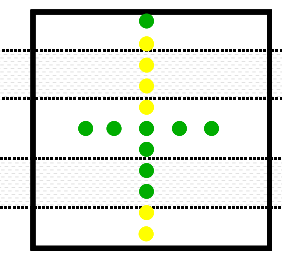

RollTest2

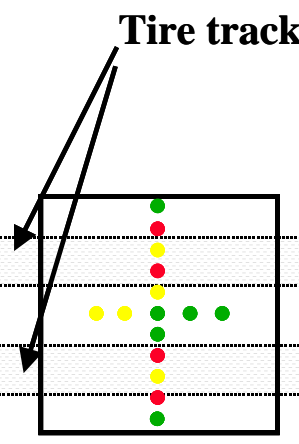

RollTest3

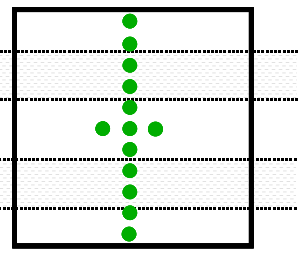

StartStop2

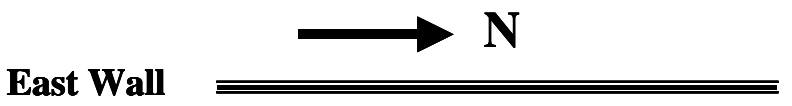

\section{Not to scale}

Figure 7. Results of the ultrasonic damage assessment after $\mathbf{5 0 0}$ traverses of the transporter. Note location of sub-surface damage relative to tire tracks.
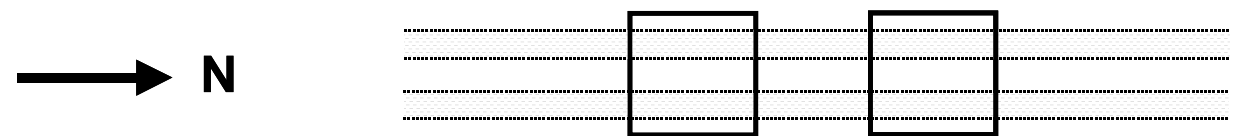

RollTest4 RollTest5

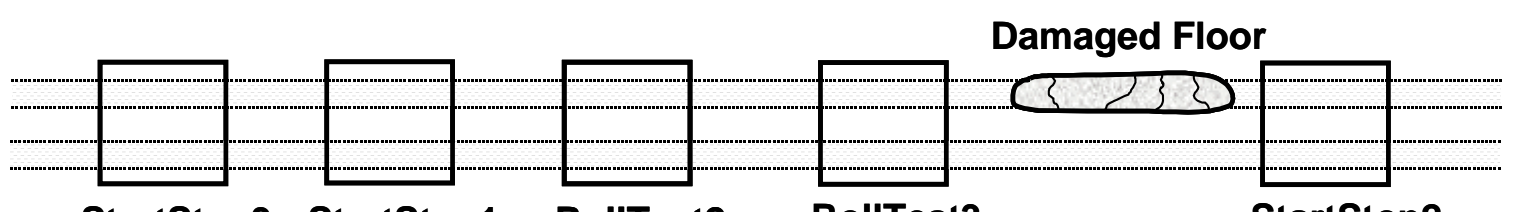

StartStop3 StartStop1 RollTest2 RollTest3

StartStop2

\section{East Wall}

Figure 8. Results of the ultrasonic damage assessment after 900 traverses of the transporter. Note location of sub-surface damage relative to wheel tracks. 
- Good

Slight damage

- Major damage
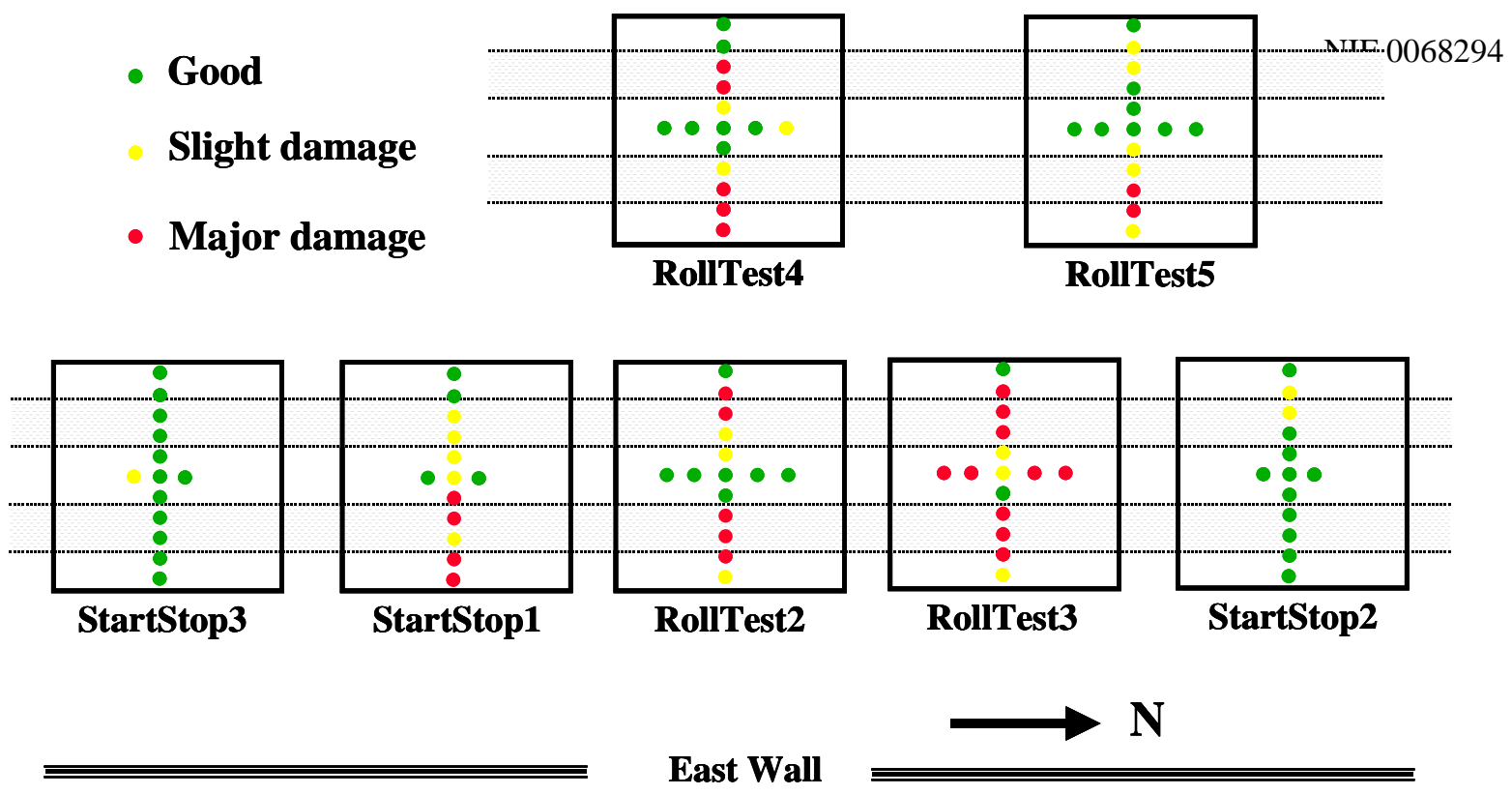

RollTest2

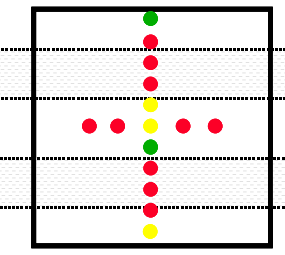

RollTest3

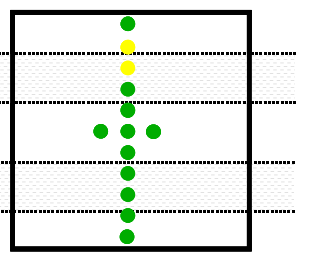

StartStop2

East Wall

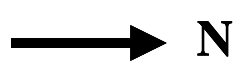

\section{Not to scale}

Figure 9. Map of ultrasonic data acquisition locations. Front wheel stopped at StartStop3 and rear wheel stopped at StartStop1. Note location of visible floor damage. RollTest4 and RollTest5 areas are where the other set of wheels traversed and was evaluated only after 900 traverses. No visible damage was noted under these wheels.

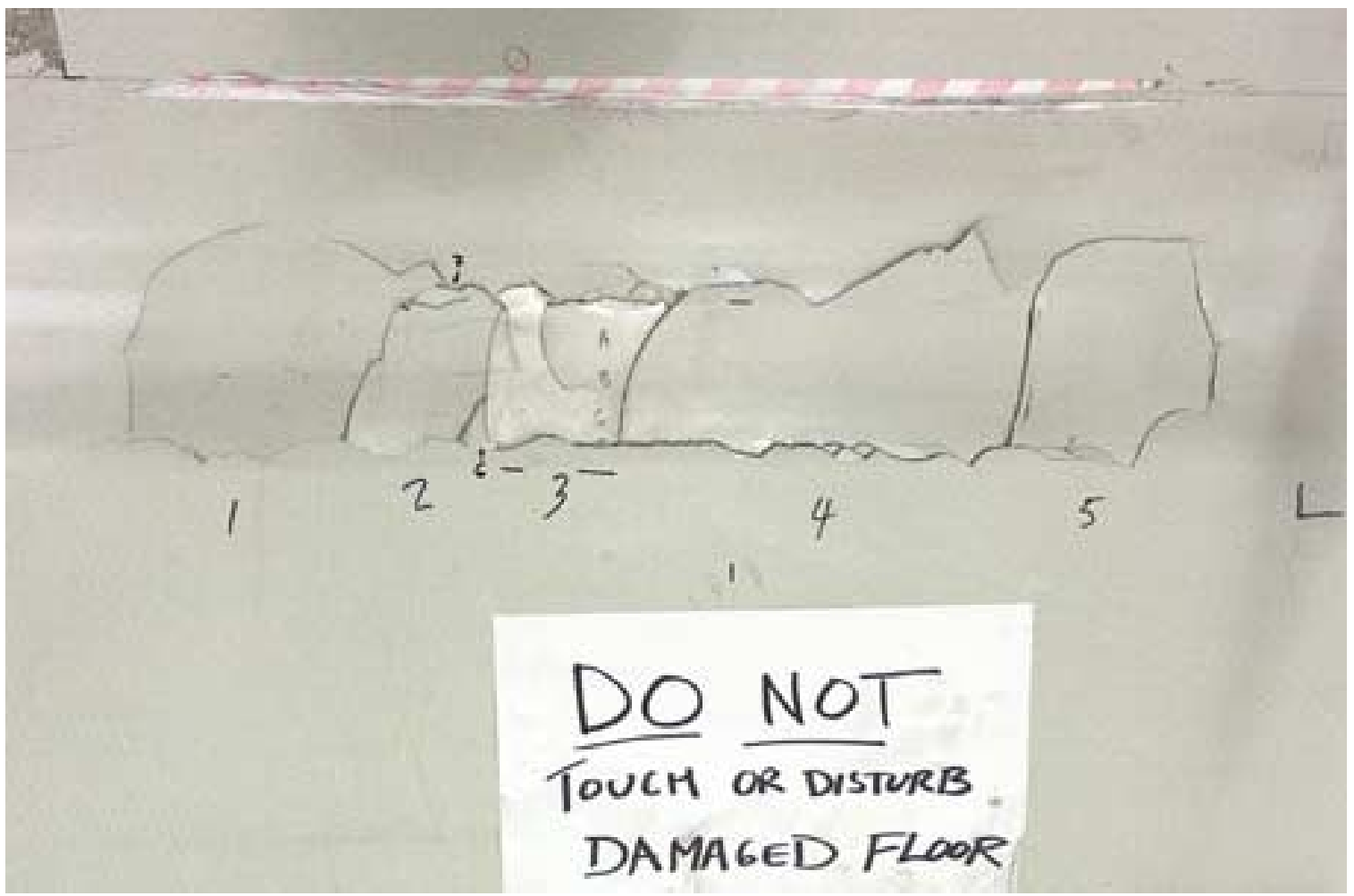

Figure 10. Photograph of the damaged floor caused by the transporter traversing the same track 900 times. 


\section{Conclusions}

1. Ultrasonic evaluation detects the onset of damage in the grout layer caused by loading from the transporter. To quantify the ultrasonic measurements we need to capture ultrasonic data during a controlled destructive test of a floor section.

2. For a fully loaded transporter, turning the casters in place produces sub-surface damage in as few as 12 turns depending on how clean the floor and the tires are.

3. Rolling loading will damage the floor in as few as 32 traverses and catastrophic failure may occur at approximately 1000 passes.

This work was performed under the auspices of the U.S. Department of Energy by the University of California, Lawrence Livermore National Laboratory under contract No. W7405-Eng-48. 


\title{
Appendix A:
}

\section{Experimental Plan: \\ Ultrasound Investigation of the LTAB Flooring}

\author{
William H. Gourdin
}

April 13, 2001

\section{Baseline Determination.}

Objective: Determine the ultrasound signature in an area of the floor that is known not to have been subjected to significant loads.

\section{Procedure:}

1. Select an area of the floor that has not been subjected to heavy loads (e.g. a corner).

2. Perform 13 ultrasound measurements 1" apart along a line arbitrarily selected in this area.

3. Assess.

\section{Effect of turning wheels in place.}

Objective: Confirm the proposed mechanism of floor failure.

\section{Procedure:}

NOTE: If possible, use water as the acoustic coupling medium. Use of the acoustic gel may leave residues on the floor that are difficult to remove and could modify the coefficient of friction between the floor and the wheels.

1. Select an area 12" square under one front caster and one rear caster; mark the center of each.

2. Draw orthogonal lines through the center, on in the direction of rolling, one normal to the direction of rolling. Mark from center for the front caster: 1.5", 1.5", 1"; for the rear caster: 1", 1.25", 1.25", 1.25", 1.25", 1" (assures measurements at the centerline of each wheel).

3. Perform ultrasound measurements at each location including the center (20 measurements total); compare to baseline.

4. Position transporter so wheels are on centers of selected areas

5. Turn wheels $90^{\circ}$ in place; move transporter laterally to permit access to areas

6. Perform measurements as in item 3 above 
7. Reposition transporter over centers of each area.

8. Turn wheels $360^{\circ}$ in place; move transporter laterally.

9. Perform measurements as in item 3 above.

10. Reposition transporter over centers of each area.

11. Turn wheels $360^{\circ}$ in place; move transporter laterally.

12. Perform measurements as in item 3 above.

13. Assess.

14. Perform additional cycles of items 4-6 as appropriate.

\section{Effect of transporter rolling.}

Objective: Determine whether rolling loads produced by movement of the transporter cause sub-surface floor damage that may lead to floor failure, and, if so, the extent of such damage.

\section{Procedure:}

NOTE: If possible, use water as the acoustic coupling medium. Use of the acoustic gel may leave residues on the floor that are difficult to remove and could modify the coefficient of friction between the floor and the wheels.

1. Select two rectangular areas under on front and one rear caster, away from the areas used for turn testing, 8 " wide by 12 " long for the front caster, 12 " wide by 12 " long for the read (widths ensure coverage across the entire footprint of the wheels, length is arbitrary --- is this reasonable?)

2. Normal to rolling direction, mark for the front caster: 1.5", 1.5", 1 "; for the rear caster: 1", 1.25", 1.25", 1.25", 1.25", 1" (assures measurements at the centerline of each wheel). Along rolling direction mark 1" intervals on either side of center.

3. Perform ultrasound measurements at each location including the center (24 measurements total); compare to baseline.

4. Roll transporter over areas in one direction only (one pass).

5. Perform measurements as in item 3 .

6. Roll transporter over areas twice (once each direction)

7. Perform measurements as in item 3 .

8. Roll transporter over areas four times.

9. Perform measurements as in item 3.

10. Assess.

11. Repeat rolling/measurement cycle as desired, doubling the number of passes each time.

12. Assess. 


\title{
Appendix B:
}

\section{Ultrasonic Data Acquisition}

\author{
Paul Souza
}

We collected ultrasonic waveforms from the NIF Laser Bay Transporter Floor on May 14 through May 16, 2001. The waveforms are used to detect damage to the floor caused by the Automated Guided Vehicle (AGV).

Test areas were sketched on the floor in an area were the Automated Guided Vehicle (AGV) had never been driven (Figures AB 1 and AB 2). These areas were identified as StartStop3, StartStop1, RollTest2, RollTest3, and StartStop2. The AGV was driven back and forth over the test areas a predetermined number of passes, $0,2,4,8,16,32,64,128,256$, respectively. Ultrasonic waveforms were collected from these test areas after a set of passes was completed. Plexiglas templates were used to locate the transducer with repeatability in each test area. The locations where the transducer is placed are named Y1, Y2, Y3..., X1, $\mathrm{X} 2 \ldots$, etc, see Figure AB 1.

The ultrasonic waveforms are digitally stored. All of the waveforms are stored in a main directory called NIF_RollTestData_sorted. The main directory contains subdirectories named after each of the test areas, i.e. StartStop1. The secondary directories contain additional subdirectories that contain the waveform files (*.pan). These subdirectories are named for the test area plus the data point template location, i.e. StartStop1_ DataPoint_X05_waveforms. The .pan waveform files contained in these directories are named for the test area plus the template location plus the number of passes the AGV traversed the test area, i.e. StartStop1_064passes_x05.pan.

A Panametrics Epoch III model 2300 portable pulser/receiver was used along with a Panametrics M109, $5 \mathrm{MHz}$ / 0.5" diameter contact transducer serial \# 124530 to transmit and receive the sound. The transducer was equipped with a plexiglas delay line that is 0.35 inches (6.62 microseconds) in length. The following pulser/settings remained constant and were as follows: 


$\begin{array}{ll}\text { Damping: } & 50 \text { ohms } \\ \text { Pulser Energy: } & \text { Low } \\ \text { Range: } & 1.084 \text { inches } \\ \text { Velocity: } & 0.3178 \text { inches per microsecond } \\ \text { Zero offset: } & 6.515 \text { microseconds }\end{array}$

Two different pulser/receiver gain settings were used. The initial gain setting of $58 \mathrm{~dB}$ was used the first day. All of the 000passes waveforms and StartStop1_002passes waveforms used this setting. At this point because of a signal saturation issue, the gain was reduced to 55dB. The StartStop1_002passes waveforms were reacquired. The reacquired waveforms at $55 \mathrm{~dB}$ were given the designation letter ' $\mathrm{a}$ ' in their name, i.e.

StartStop1_002passes_x05a.pan. 55dB was used as the gain setting for the remainder of the test. 
Not to scale
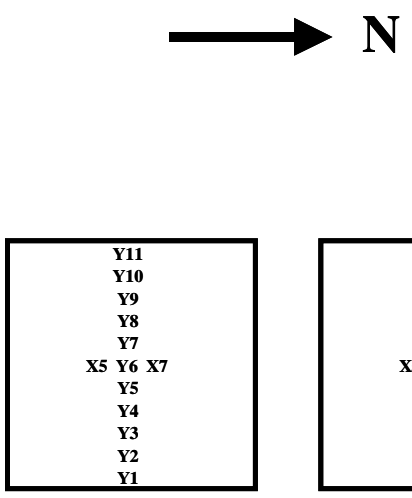

StartStop3

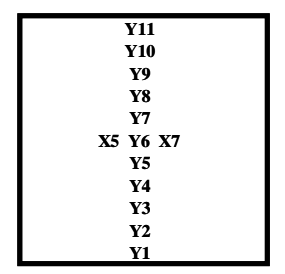

StartStop1

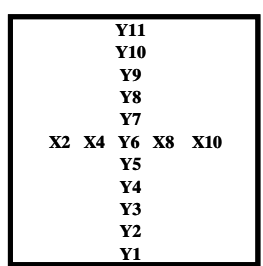

RollTest4

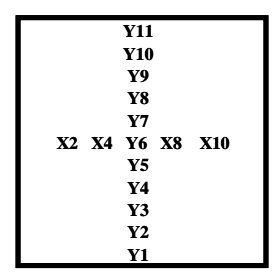

RollTest5

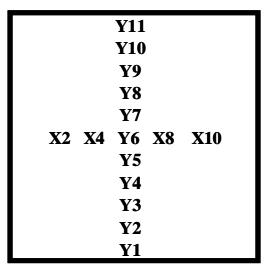

RollTest2

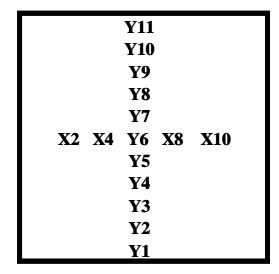

RollTest3

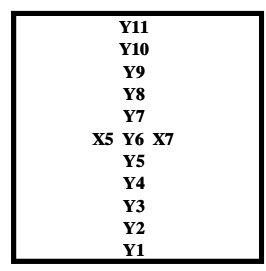

StartStop2

\section{East Wall}

Figure AB1. Diagram of ultrasonic data acquisition locations for traversal test. The floor sustained failure at a location between RollTest3 and StartStop2. Note that these locations are not to scale.
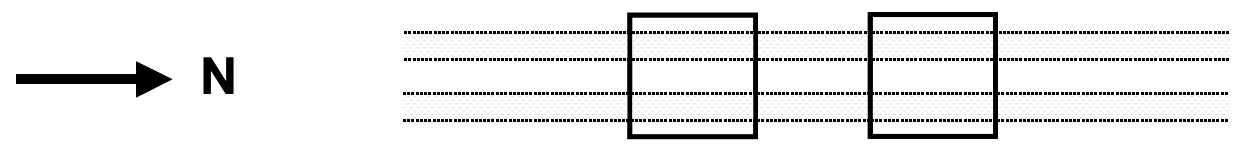

RollTest4 RollTest5

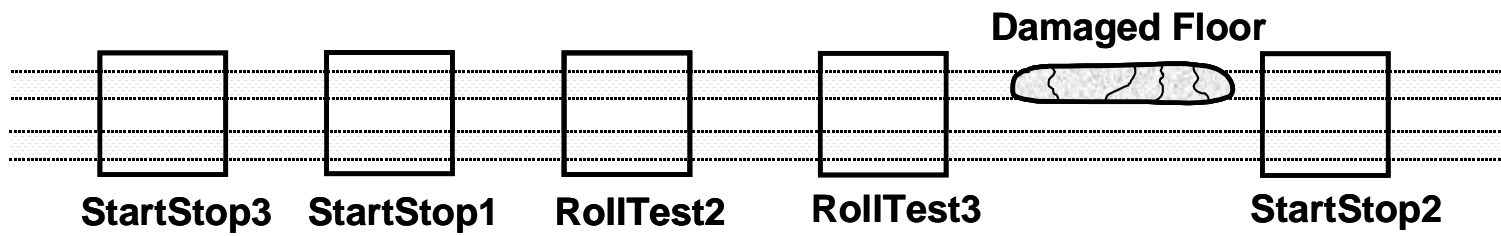

East Wall

Figure $A B$ 2. Locations of ultrasonic data acquisition relative to damaged area. This drawing is somewhat to scale. 